\title{
Failure Estimates for SiC Power MOSFETs in Space Electronics
}

\author{
Kenneth F. Galloway ${ }^{1, *}$, Arthur F. Witulski ${ }^{1}$, Ronald D. Schrimpf ${ }^{1}$ (D), Andrew L. Sternberg ${ }^{1}$, \\ Dennis R. Ball ${ }^{1}$, Arto Javanainen ${ }^{2,3}$ (D), Robert A. Reed ${ }^{1}$, Brian D. Sierawski ${ }^{1}$ (D) and \\ Jean-Marie Lauenstein 4 (iD \\ 1 Institute for Space and Defense Electronics, Department of Electrical Engineering and Computer Science, \\ Vanderbilt University, VU Station B 351824, 2301 Vanderbilt Place, Nashville, TN 37235-1824, USA; \\ arthur.f.witulski@vanderbilt.edu (A.F.W.); ron.schrimpf@vanderbilt.edu (R.D.S.); \\ andrew.l.sternberg@vanderbilt.edu (A.L.S.); dennis.r.ball@vanderbilt.edu (D.R.B.); \\ Robert.Reed@vanderbilt.edu (R.A.R.); brian.sierawski@vanderbilt.edu (B.D.S.) \\ 2 Department of Electrical Engineering and Computer Science, Vanderbilt University, VU Station B 351824, \\ 2301 Vanderbilt Place, Nashville, TN 37235-1824, USA; arto.javanainen@jyu.fi \\ 3 Department of Physics, University of Jyvaskyla, P.O. Box 35, FI-40014 Jyvaskyla, Finland \\ 4 NASA Goddard Space Flight Center, Code 561.4, Greenbelt, MD 20771, USA; Jean.M.Lauenstein@nasa.gov \\ * Correspondence: ken.galloway@vanderbilt.edu; Tel.: +1-615-343-0312
}

Received: 27 April 2018; Accepted: 20 June 2018; Published: 22 June 2018

\begin{abstract}
Silicon carbide ( $\mathrm{SiC}$ ) power metal-oxide-semiconductor field effect transistors (MOSFETs) are space-ready in terms of typical reliability measures. However, single event burnout (SEB) due to heavy-ion irradiation often occurs at voltages $50 \%$ or lower than specified breakdown. Failure rates in space are estimated for burnout of $1200 \mathrm{~V}$ devices based on the experimental data for burnout and the expected heavy-ion linear energy transfer (LET) spectrum in space.
\end{abstract}

Keywords: single event effects; heavy ions; silicon carbide; single-event burnout; power devices; power MOSFETs; reliability; failure rates

\section{Introduction}

Silicon carbide ( $\mathrm{SiC}$ ) has excellent properties for power device applications. In comparison to silicon, it has higher breakdown field and higher thermal conductivity. SiC devices are ideally suited to high voltage, high power-density power converter applications, both on Earth and in space. These devices, in comparison to silicon devices, have advantages in breakdown voltage $(\sim 10 \times \mathrm{Si})$, low on-resistance $(\sim 1 / 100 \mathrm{Si})$, high temperature operation $(\sim 3 \times \mathrm{Si})$ and high thermal conductivity $(\sim 10 \times \mathrm{Si})$ [1]. The typical terrestrial electrical reliability results for $\mathrm{SiC}$ power devices are excellent [2-6]. Advancements in the crystal quality of $4 \mathrm{H}-\mathrm{SiC}$ substrates and epitaxial growth capabilities, improvements in $4 \mathrm{H}-\mathrm{SiC}$ device gate oxides, and innovation in processing has yielded a significant commercial presence for $\mathrm{SiC}$ power metal-oxide-semiconductor field effect transistors (MOSFETs).

For spaceborne electronics, consideration must be given to the radiation response of a device. SiC power MOSFETs are affected by total ionizing dose (TID), but, typically, TID response is acceptable at a total dose $<100 \mathrm{krad}(\mathrm{Si})$, and, depending on the application, devices can be useful up to $300 \mathrm{krad}(\mathrm{Si})$ [7]. However, the sensitivity of SiC power devices (both MOSFETs and diodes) to energetic heavy ions has been found to be higher than might be expected with both leakage current degradation and single event burnout being observed.

In this paper, we briefly discuss typical SiC power MOSFET reliability evaluations and the data for the degradation and burnout of $1200 \mathrm{~V} \mathrm{SiC}$ power MOSFETs. Based on the available burnout versus 
linear energy transfer (LET) experimental data and an approximation of the heavy-ion integrated LET spectrum expected in space, we estimate the worst-case failure rate for $\mathrm{SiC}$ power MOSETs in several space orbits.

\section{Brief Review of SiC Mosfet Electrical Reliability}

Since their commercial introduction in about 2010, the reliability of SiC power MOSFETs has been carefully examined by a number of researchers [2-6]. Early on, it was expected that the weakest element in a $4 \mathrm{H}-\mathrm{SiC}$ power MOSFET would be the MOS gate dielectric. However, improvements in materials and fabrication techniques have yielded reliable $4 \mathrm{H}-\mathrm{SiC}$ gate oxides. A time dependent dielectric breakdown (TDDB) study of gate oxides in $4 \mathrm{H}-\mathrm{SiC}$ showed that a 100 -year lifetime at a temperature of $375{ }^{\circ} \mathrm{C}$ can be expected if the oxide electric field $E_{o x}$ is lower than $3.9 \mathrm{MV} / \mathrm{cm}$, suggesting that catastrophic failure of the gate oxide due to electrical stress is a manageable reliability issue for these devices [3]. High temperature tests on commercial devices from two sources indicated that the $1200 \mathrm{~V}$ $\mathrm{SiC}$ MOSFETs tested are capable of operating with junction temperatures over $250^{\circ} \mathrm{C}$ for more than $500 \mathrm{~h}$ and an estimated $5 \times 10^{4} \mathrm{~h}$ at $150^{\circ} \mathrm{C}$.

Accelerated life high temperature reverse bias (HTRB) tests and time dependent dielectric breakdown (TDDB) tests of gate oxides in $4 \mathrm{H}-\mathrm{SiC}$ have been carried out on $1200 \mathrm{~V}$ production devices [5,6]. This work estimated TDDB mean time to failure values (MTTF) of nearly $10^{7} \mathrm{~h}$ in continuous operation with $20 \mathrm{~V}$ applied to the gate. The HTRB test lifetime extrapolation yields over $10^{7} \mathrm{~h}$ at $960 \mathrm{~V}$ continuous operation and somewhat more than $10^{5} \mathrm{~h}$ at $1200 \mathrm{~V}$. Field failure data are less than 5 FIT ( 1 FIT $=1$ failure per billion hours) [5]. These reliability assessments [5,6] of commercially available devices indicate mean device lifetimes of more than 1000 years under normal device operating conditions.

Consequently, in terms of electrical reliability tests, $\mathrm{SiC}$ power MOSFETs are well suited for applications requiring high voltage and high power-density. However, for spaceborne electronics, the natural space radiation environment must be factored into the reliability considerations. We also note that these devices are susceptible to burnout due to terrestrial neutrons and their terrestrial radiation reliability has been evaluated by Lichtenwalner et al. [6] and Akturk et al. [8].

\section{Radiation Effects Data on 1200 V SiC Power MOSFET Devices}

SiC power MOSFETs may undergo catastrophic single event burnout (SEB) when exposed to energetic heavy ions or protons [9-11]. Two types of single-event effects are observed when SiC power MOSFET devices are irradiated with heavy ions: degradation and catastrophic failure $[10,11]$. Figure 1 displays published single event burnout data from four different experiments examining SEB for $1200 \mathrm{~V} \mathrm{SiC}$ power MOSFETs [9-11]. These $1200 \mathrm{~V}$ devices were manufactured by Wolfspeed (a CREE Company, Durham, NC, USA) [12]. There were differences in the on-resistance and current rating depending on the particular data set.

Note that, for LETs $>10 \mathrm{MeV}-\mathrm{cm}^{2} / \mathrm{mg}$, all devices fail at reverse voltages significantly below the device rated voltage of $1200 \mathrm{~V}$. In addition to SEBs, permanent damage to the device is manifested as an increase in drain leakage with the higher LET ions, similar to that observed in SiC Schottky barrier diodes [13]. No leakage current increase was observed for LETs $<5 \mathrm{MeV}-\mathrm{cm}^{2} / \mathrm{mg}$, including protons, before SEBs were observed. Witulski et al. [9] used technology computer-aided design (TCAD) simulations to demonstrate that turn-on of the parasitic bipolar transistor inherent in the $\mathrm{SiC}$ power MOSFET structure is part of the physical mechanism leading to catastrophic SEB failure in these devices. This is similar to what has been observed for SEB in silicon power MOSFETs. 


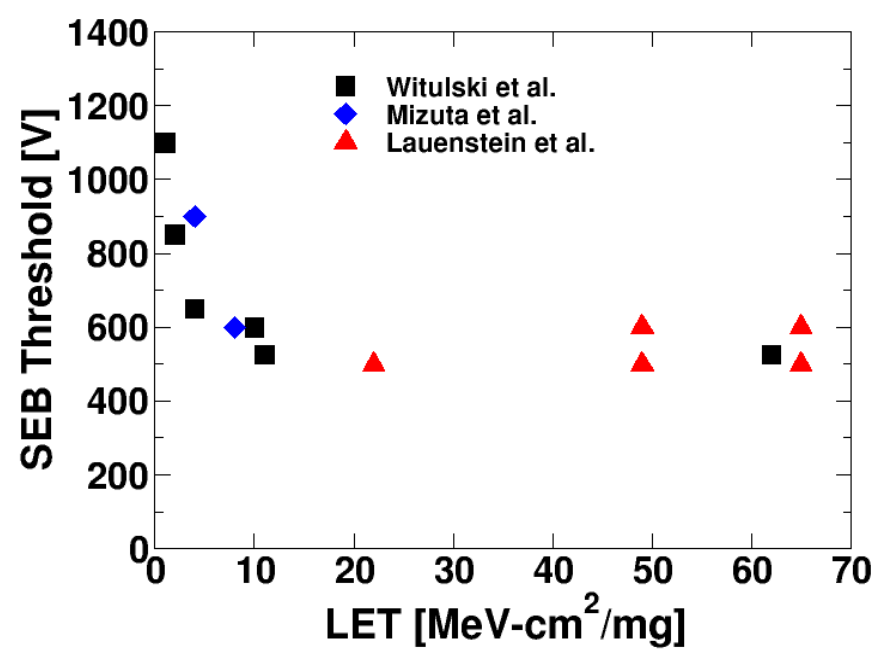

Figure 1. Experimental measurements of single event burnout (SEB) threshold voltage versus heavy-ion linear energy transfer (LET) for $1200 \mathrm{~V} \mathrm{SiC} \mathrm{Power} \mathrm{metal-oxide-semiconductor} \mathrm{field} \mathrm{effect} \mathrm{transistors}$ (MOSFETs). Data from [9-11].

\section{Estimate of the Worst-Case Failure Rate for SiC Power MOSFETs in Space}

Estimating the failure rate (FR), the failure in time or FIT rate, and the mean time between failures (MTBF), requires an estimate of the cross section for SEB failure and the flux of particles at an LET or higher that will cause this failure. Since SEB is a catastrophic failure, we use MTTF (mean time to failure) rather than MTBF. We will use a modification of the method proposed by Dashdondog et al. [14], based on worst-case assumptions. This method is similar to that of Titus et al. [15], as applied by Lauenstein et al. [16].

The $1200 \mathrm{~V}$ devices fail at approximately $500 \mathrm{~V}$ for any LET $>10 \mathrm{MeV}-\mathrm{cm}^{2} / \mathrm{mg}$. Thus, the cross section for SEB failure is assumed to have reached its saturation values for LET $>10 \mathrm{MeV}-\mathrm{cm}^{2} / \mathrm{mg}$. Since the bias boundary for SEB is almost constant for LET $>10 \mathrm{MeV}-\mathrm{cm}^{2} / \mathrm{mg}$, we will define SEB failure as operation at a reverse voltage greater than $500 \mathrm{~V}$ for any LET $>10 \mathrm{MeV}-\mathrm{cm}^{2} / \mathrm{mg}$. The failure rate $(\mathrm{FR})$ under these conditions can be expressed as

$$
\mathrm{FR}=\sigma \int \operatorname{Flux}(\mathrm{LET}) \mathrm{dLET},
$$

where $\sigma$ is the saturated MOSFET SEB cross-section and the integral is evaluated over the ion flux as a function of LET. The integral is to be evaluated for LETs greater than $10 \mathrm{MeV}-\mathrm{cm}^{2} / \mathrm{mg}$ (the cross section is assumed to be zero for LET values lower than the SEB threshold value). The value of this integral depends on the spacecraft mission or orbit and solar activity. To estimate the failure rate for $\mathrm{SiC}$ power MOSETs in space, we make some assumptions about the SEB cross-section and the integrated LET spectrum expected.

The devices tested by Witulski et al. [9] and represented by the data points in Figure 1 have a chip size of approximately $2 \mathrm{~mm}$ by $3 \mathrm{~mm}$. Since the cross-section for SEB is not known from experiments, a simple approximation is made based on the chip area $\left(6 \times 10^{-2} \mathrm{~cm}^{2}\right)$. However, the entire chip is not sensitive. In addition, the time when the device is reverse biased is less than $100 \%$. Taking the sensitive area as $50 \%$ of the die area and the duty-cycle to be $50 \%$, this reduces the effective cross-section, independent of LET, to

$$
\sigma=1.5 \times 10^{-2} \mathrm{~cm}^{2} .
$$

For our estimates, we use LET distributions from Xapsos et al. [17] and from CREME96 [18] as shown in Figure 2. The Xapsos et al. spectrum is based on a probabilistic model of cumulative solar heavy ion spectra behind 100 mils of aluminum during a solar maximum time period. The potential 
impact of inelastic proton interactions is not considered. Only a very small fraction of the recoils from proton nuclear reactions have LETs $>10 \mathrm{MeV} \mathrm{cm}^{2} / \mathrm{mg}$ and would most likely contribute a negligible amount to the failure rate $[19,20]$.

The estimate here is based on the $99 \%$ confidence level curve, which Xapsos et al. consider as appropriate for use as a conservative design estimate of the single-event rate due to solar particles during solar max. The integral for LET greater than $10 \mathrm{MeV}-\mathrm{cm}^{2} / \mathrm{mg}$ results in

$$
\int \operatorname{Flux}(\mathrm{LET}) \mathrm{dLET}=10 \mathrm{~cm}^{-2} \text { day }^{-1} \text {. }
$$

This choice of effective cross section and of an integrated LET spectrum yields

$$
\mathrm{FR}=6.25 \times 10^{-3} / \mathrm{h} \text { and } \mathrm{FIT}=6.25 \times 10^{6} .
$$

This FIT value leads to a mean time to failure (MTTF) of $160 \mathrm{~h}$. This estimate, however, neglects a number of factors including possible angular effects.

SEB is most likely for an ion strike near normal to the top surface of the device. There is no published data on the angular effects in $\mathrm{SiC}$ power MOSFETs. If we assume that the device is sensitive to SEB for strikes $\pm 15^{\circ}$ to normal [21,22] and that in the spacecraft the environment is isotropic, only about $1 / 67$ of the $4 \pi$ steradian geometry is available for SEB. This leads would to a reduction in the calculated FIT by a factor of approximately 70. Even if we assume that the FIT is too high by a factor of 70, the MTTF is still on the order of $11,200 \mathrm{~h}$ or less than 1.5 years. This is a high FIT rate compared to that due to other reliability concerns. The range of FITs for most components is 100 to 1000 , based on electrical reliability.

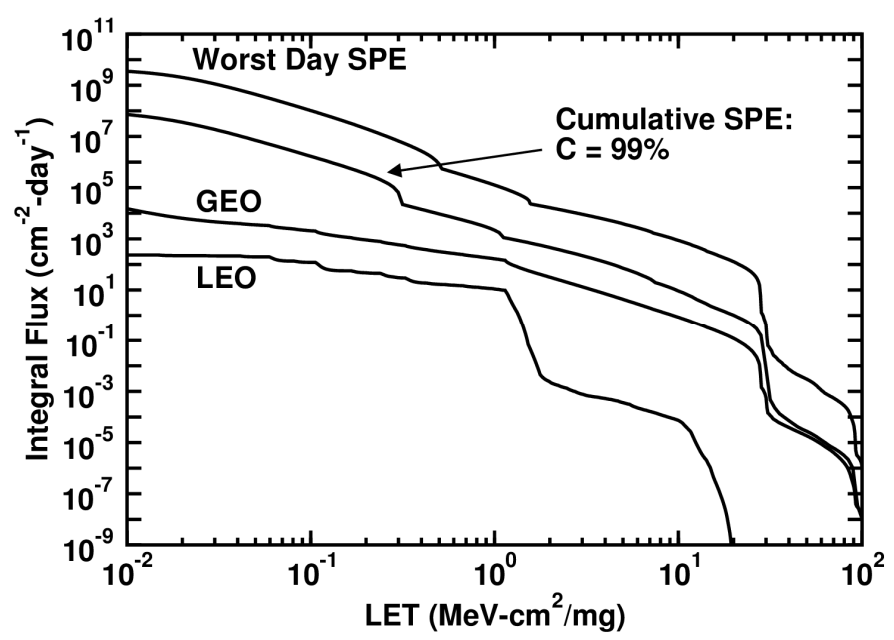

Figure 2. Worst day solar particle event (SPEW) from CREME96 [18]. GEO and LEO are solar minimum spectra from CREME96 [18]. Cumulative solar particle event spectra at the $99 \%$ confidence levels after Xapsos et al. [17]. Results for 100 mils aluminum shielding. GEO-geostationary orbit, often referred to as a geosynchronous equatorial orbit (GEO); LEO-low Earth orbit, common usage in discussing satellites.

If we consider the worst day solar particle spectrum as given by CREME96 [18], which is based on the 1989 event averaged over one day as determined from GOES-6 and -7 instrumentation, we obtain

$$
\int \operatorname{Flux}(\mathrm{LET}) \mathrm{dLET}=10^{3} \mathrm{~cm}^{-2} \text { day }^{-1},
$$

which yields

$$
\mathrm{FIT}=6.25 \times 10^{8} \text { and MTTF }=1.6 \mathrm{~h} .
$$


Table 1 tabulates the integral evaluated for LET greater than $10 \mathrm{MeV}-\mathrm{cm}^{2} / \mathrm{mg}$ behind 100 mils of aluminum shielding, the worst-case FIT and the MTTF for the episodic cases considered above and for two additional long-term average environments (GEO, LEO) as calculated using CREME96 [18].

Table 1. Value of integral LET spectra (Int.) and SiC MOSFET FIT and MTTF for several space scenarios. All results assume 100 mils of aluminum shielding.

\begin{tabular}{cccc}
\hline Spectrum & $\begin{array}{c}\text { Int. } \\
\text { (no./cm }\end{array}$-Day) & $\begin{array}{c}\text { FIT } \\
\text { (1 Per Billion Hours) }\end{array}$ & $\begin{array}{c}\text { MTTF } \\
\text { (Hours) }\end{array}$ \\
\hline SPEW & 1000 & $6.25 \times 10^{8}$ & 1.6 \\
SPE & 10 & $6.25 \times 10^{6}$ & 160 \\
GEO & 0.9 & $5.6 \times 10^{5}$ & 1786 \\
LEO & $1 \times 10^{-4}$ & 62.5 & $1.6 \times 10^{7}$ \\
\hline
\end{tabular}

SPEW = worst day solar particle event (SPE) from CREME96; SPE = cumulative SPE at solar max., $99 \%$ confidence from Xapsos; GEO = geostationary Earth orbit during solar min. from CREME96; LEO = low Earth orbit during solar min. from CREME96.

As seen from the values in Table 1, the FIT and MTTF vary significantly with mission and solar activity. In low earth orbit with typical solar activity, the devices should operate for years. However, in a worst case solar event, the device may only last a few hours, if that long. Results given in the table are illustrated in Figure 3. In GEO, the devices are expected to fail in relatively short times. In low earth orbit with typical solar activity, the devices should operate for years. In LEO at a solar max, you might expect the time to failure to be reduced, but the ion flux will be modified by the earth's magnetosphere.

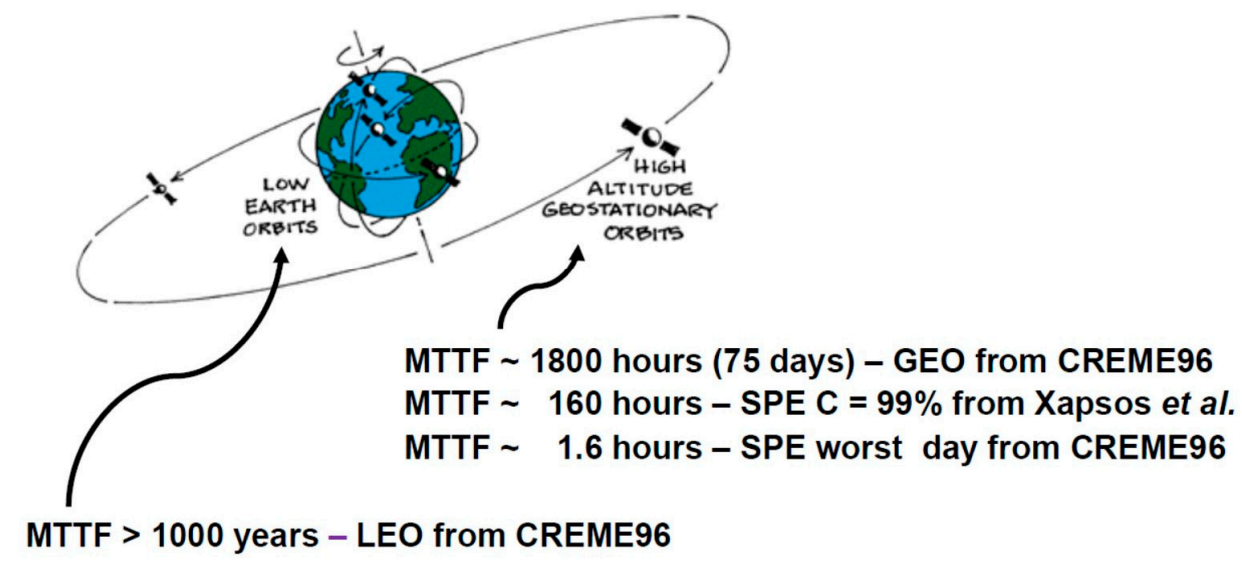

Figure 3. SEB failure rate for two potential orbits for a $1200 \mathrm{~V} \mathrm{SiC}$ power MOSFET. Image from Department of Commerce, National Oceanic and Atmospheric Administration.

\section{Discussion}

In this work, we have considered $1200 \mathrm{~V} \mathrm{SiC} \mathrm{MOSFET} \mathrm{devices} \mathrm{and} \mathrm{estimated} \mathrm{the} \mathrm{failure} \mathrm{rate}$ in the space radiation environment for several different possible missions. Experimental results have demonstrated that these devices fail at approximately $500 \mathrm{~V}$ for any LET $>10 \mathrm{MeV}-\mathrm{cm}^{2} / \mathrm{mg}$. We estimate the SEB failure rate based on a constant cross section for operation at a reverse voltage greater than $500 \mathrm{~V}$ for any LET $>10 \mathrm{MeV}-\mathrm{cm}^{2} / \mathrm{mg}$.

A number of assumptions have been made to arrive at the estimates given above in Table 1 and the uncertainty in these estimates for FIT and MTTF may be relatively large. Even so, regardless of the assumptions, it appears that $\mathrm{SiC}$ power MOSFETs have the potential for significant failure rates due to heavy ion radiation exposure in the space radiation environment. 
There may be situations where size, weight, and power requirements justify the use of $\mathrm{SiC}$ power MOSFETs in space. The Orion multi-purpose crew vehicle (MPCV) was developed by NASA to send crews of up to six astronauts on missions through space that could last as long as six months. As a secondary mission, the craft will also be used as a backup vehicle for cargo and crewed missions to the International Space Station. In addition, $1200 \mathrm{~V} \mathrm{SiC}$ power MOSFETs are being used for this system [23]; however, these devices are being used with the voltage significantly derated. Additionally, $\mathrm{SiC}$ power MOSFETs are in use for the NASA MMS (Magnetospheric Multiscale) spacecraft.

This worst-case analysis indicates that, at this time, thorough heavy ion testing of any commercially available SiC MOSFET component proposed for utilization in spaceborne electronic systems is needed. Currently, any use of $1200 \mathrm{~V} \mathrm{SiC} \mathrm{MOSFETs} \mathrm{would} \mathrm{require} \mathrm{significant} \mathrm{de-rating.}$ A $1200 \mathrm{~V}$ device should not be used at voltages above $500 \mathrm{~V}$ in any radiation environment with

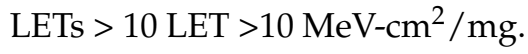

Author Contributions: A.L.S., A.J., and J.-M.L. provided experimental data and insights; K.F.G., A.F.W., R.D.S., D.R.B., R.A.R. and B.D.S. contributed to the analysis; K.F.G. wrote the paper.

Funding: Support for this work at Vanderbilt provided by NASA ESI Grant No: NNX17AD09G, at NASA Goddard by the NEPP Program, and at University of Jyväskylä by ESA/ESTEC Contract No. 4000111630/14/NL/PA and Academy of Finland Project No. 2513553.

Acknowledgments: We would like to thank Mike Alles and Robert Johnson at Vanderbilt, Ari Virtanen at the University of Jyvaskyla, Dave Grider, Dan Lichtenwalner, and Brett Hull at Wolfspeed, and Ray Ladbury and Mike Xapsos at NASA Goddard Space Flight Center for useful discussions. This manuscript is based on a presentation at the 2018 HEART Technical Interchange Meeting, Tucson, AZ, USA, 16-17 April 2018.

Conflicts of Interest: The authors declare no conflict of interest.

\section{References}

1. Elasser, A.; Chow, T.P. Silicon Carbide Benefits and Advantages for Power Electronic Circuits and Systems. Proc. IEEE 2002, 90, 969-986. [CrossRef]

2. Ryu, B.; Hull, B.; Dhar, S.; Cheng, L.; Zhang, Q.; Richmond, J.; Das, M.; Agarwal, A.; Palmour, J.; Lelis, A.; et al. Performance, Reliability, and Robustness of 4H-SiC Power DMOSFETs. Mater. Sci. Forum 2010, 645, 969-974. [CrossRef]

3. Yu, L.C.; Dunne, G.T.; Matocha, K.S.; Cheung, K.P.; Suehle, J.S.; Sheng, K. Reliability Issues of SiC MOSFETs: A Technology for High-Temperature Environments. IEEE Trans. Device Mater. Reliab. 2010, 10, 418-426. [CrossRef]

4. Maxime, B.; Remy, O.; Thibault, C.; Pierre, P.; Sebestion, O.; Dominique, T. Electrical performances and reliability of commercial SiC MOSFETs at high temerpature and in SC conditions. In Proceedings of the 2015 17th European Conference on Power Electronics and Applications (EPE'15 ECCE-Europe), Geneva, Switzerland, 8-10 September 2015.

5. Gajewski, D.S.; Hull, B.; Lichtenwalner, D.J.; Ryu, S.-H.; Bonelli, E.; Mustain, H.; Wang, G.; Allen, S.T.; Palmour, J.W. SiC Power Device Reliability. In Proceedings of the 2016 IEEE International Integrated Reliability Workshop (IIRW), South Lake Tahoe, CA, USA, 9-13 October 2016; pp. 29-34.

6. Lichtenwalner, D.J.; Hull, B.; Van Brunt, E.; Sabri, S.; Gajewski, D.A.; Grider, D.; Allen, S.; Palmour, J.W.; Akturk, A.; McGarrity, J. Reliability Studies of SiC Vertical Power MOSFETs. In Proceedings of the 2018 IEEE International Reliability Physics Symposium (IRPS), Burlingame, CA, USA, 11-15 March 2018; pp. 2B.2-1-2B.2-6.

7. Akturk, A.; McGarrity, J.M.; Potbhare, S.; Goldsman, N. Radiation Effects in Commercial 1200 V 24 A Silicon Carbide Power MOSFETs. IEEE Trans. Nucl. Sci. 2012, 59, 3258-3264. [CrossRef]

8. Akturk, A.; Wilkins, R.; McGarrity, J.; Gersey, B. Single Event Effects in Si and SiC Power MOSFETs Due to Terrestrial Neutrons. IEEE Trans. Nucl. Sci. 2017, 64, 529-535. [CrossRef]

9. Witulski, A.F.; Ball, D.R.; Galloway, K.F.; Javanainen, A.; Lauenstein, J.-M.; Sternberg, A.L.; Schrimpf, R.D. Analysis of SEB Physics in SiC Power MOSFETs. IEEE Trans. Nucl. Sci. 2018, in press. 
10. Lauenstein, J.-M.; Casey, M.C.; Topper, A.D.; Wilcox, E.P.; Phan, A.M.; LaBel, K.A. Silicon Carbide Power Device Performance Under Heavy-Ion Irradiation. In Proceedings of the IEEE Nuclear and Space Radiation Effects Conference, Boston, MA, USA, 13-17 July 2015.

11. Mizuta, E.; Kuboyama, S.; Abe, H.; Iwata, Y.; Tamura, T.; Device, A.S. Investigation of Single-Event Damages on Silicon Carbide (SiC) Power MOSFETs. IEEE Trans. Nucl. Sci. 2014, 61, 1924-1928. [CrossRef]

12. SiC and GaN Power and RF Solutions. Available online: https://www.wolfspeed.com/ (accessed on 25 April 2018).

13. Javanainen, A.; Galloway, K.F.; Nicklaw, C.; Bosser, A.L.; Ferlet-Cavrois, V.; Lauenstein, J.M.; Pintacuda, F.; Reed, R.A.; Schrimpf, R.D.; Weller, R.A.; et al. Heavy Ion Induced Degradation in SiC Schottky Diodes: Bias and Energy Deposition Dependence. IEEE Trans. Nucl. Sci. 2017, 64, 415-420. [CrossRef]

14. Dashdondog, E.; Harada, S.; Shiba, Y.; Omura, I. Failure rate calculation method for high power devices in space applications at low earth orbit. Microelectron. Reliab. 2016, 84, 502-506. [CrossRef]

15. Titus, J.L.; Wheatley, C.F.; Wheatley, T.H.; Levinson, W.A.; Burton, D.I.; Barth, J.L.; Reed, R.A.; LaBel, K.A.; Howard, J.W.; van Tyne, K.M. Prediction of Early Lethal SEGR Failure of VDMOSFETs for Commercial Space Systems. IEEE Trans. Nucl. Sci. 1999, 46, 1640-1651. [CrossRef]

16. Lauenstein, J.-M.; Goldsman, N.; Liu, S.; Titus, J.L.; Ladbury, R.L.; Kim, H.S.; Phan, A.M.; LaBel, K.A.; Zafrani, M.; Sherman, P. Effects of Ion Atomic Number on Single-Event Gate Rupture (SEGR) Susceptibility of Power MOSFETs. IEEE Trans. Nucl. Sci. 2011, 58, 2628-2636. [CrossRef]

17. Xapsos, M.A.; Stauffer, C.; Jordan, T.; Barth, J.L.; Mewaldt, R.A. Model for Cumulative Solar Heavy Ion Energy and Linear Energy Transfer Spectra. IEEE Trans. Nucl. Sci. 2007, 54, 1985-1989. [CrossRef]

18. CRÈME Site. Available online: https://creme.isde.vanderbilt.edu/ (accessed on 25 April 2018).

19. Peterson, E.L. Soft errors due to protons in the radiation belt. IEEE Trans. Nucl. Sci. 1981, 28, 3981-3986. [CrossRef]

20. Reed, R.A.; Marshall, P.W.; Kim, H.S.; McNulty, P.J.; Fodness, B.; Jordan, T.M.; Reedy, R.; Tabbert, C.; Liu, M.S.T.; Heikkila, W.; et al. Evidence for Angular Effects in Proton-Induced Single-Event Upsets. IEEE Trans. Nucl. Sci. 2002, 49, 3038-3044. [CrossRef]

21. Javanainen, A.; Turowski, M.; Galloway, K.F.; Nicklaw, C.; Ferlet-Cavrois, V.; Bosser, A.; Lauenstein, J.-M.; Muschitiello, M.; Pintacuda, F.; Reed, R.A.; et al. Heavy-Ion-Induced Degradation in SiC Schottky Diodes: Incident Angle and Energy Deposition Dependence. IEEE Trans. Nucl. Sci. 2017, 64, 2031-2037. [CrossRef]

22. Lauenstein, J.-M.; NASA Goddard Space Flight Center, Greenbelt, MD, USA. Private Communication, unpublished work.

23. Lauenstein, J.-M.; Casey, M.C.; Samsel, I.; LaBel, K.A.; Chen, Y.; Ikpe, S.; Wilcox, T.; Phan, A.; Kim, H.; Topper, A.D. Silicon Carbide Power Devices and Integrated Circuits. In Proceedings of the NASA Electronic Parts and Packaging Program (NEPP) Electronics Technology Workshop (ETW), Greenbelt, MD, USA, 26-29 June 2017.

(C) 2018 by the authors. Licensee MDPI, Basel, Switzerland. This article is an open access article distributed under the terms and conditions of the Creative Commons Attribution (CC BY) license (http://creativecommons.org/licenses/by/4.0/). 